\title{
Sustained generation of peroxide from the air by carbon nano onion under visible light to combat RNA virus
}

\author{
ANKIT SAMANTA ${ }^{\mathrm{a}}$, SUBRATA GHOSH ${ }^{\mathrm{b}}$ and SABYASACHI SARKAR ${ }^{\mathrm{c}, *}$ (1) \\ ${ }^{a}$ Centre for Healthcare Science and Technology, Indian Institute of Engineering Science and Technology, \\ Shibpur, Botanic Garden, Howrah, West Bengal 711103, India \\ ${ }^{\mathrm{b}}$ Department of Chemistry, Indian Institute of Engineering Science and Technology, Shibpur, Botanic \\ Garden, Howrah, West Bengal 711103, India \\ ${ }^{\mathrm{c}}$ Department of Applied Chemistry, Ramakrishna Mission Vidyamandira, Belur Math, Howrah, \\ West Bengal 711202, India \\ E-mail: abya@iitk.ac.in; protozyme@gmail.com
}

MS received 5 August 2021; revised 15 November 2021; accepted 16 November 2021

\begin{abstract}
Carbon nano onion (CNO) from dried grass has been synthesized by carbonization in the size range, 20 to $100 \mathrm{~nm}$. This shows catalytic property to transform aerial oxygen under visible light to generate reactive oxygen species (ROS). A concept has been presented herein to show that this CNO even under room light generates hydrogen peroxide which inhibits WSN influenza virus (H1N1). The advantage of introducing CNO, synthesized from a cheap source to cater to the global need, is to sterilize infected hospitals indoor and outdoor, aircraft carriers, air conditioner vents due to its sustained conversion of air to ROS. Thus, CNO use could prevent frequent evacuation as used by conventional sanitisers to sterilize infected places from other RNA virus and hospital pathogens under COVID-19 pandemic.
\end{abstract}

Keywords. Water-soluble CNO; Peroxide generator; catalyst; H1N1 virus; COVID-19.

\section{Introduction}

The pandemic onslaught of COVID-19 forced the world out of gear for months and there is no visualization of its end soon. To combat this, the fast development of its vaccine is a necessary measure that is difficult to achieve in the best form because of its fast mutation. The alternate is the development of a dedicated drug for its remediation. Both the processes are related to the intrinsic individual subject for treatment. Extrinsic defence measure to control the spreading of any virus is related to sanitization indoor and outdoor. This is based on spraying tested chemicals like dilute sodium hypochlorite. Hydrogen peroxide is typically used to create microbe and virus free hard surfaces and medical equipment and its excess is spontaneously decomposed to benign oxygen and water. For limited and localized applications alcoholbased sanitizer or soap water besides, UV light is used. $^{1,2}$ The pertinent question at this point is how hospitals, public transport carriers, trauma centre, or even quarantine surveillance places could be made

*For correspondence

Published online: 12 January 2022 safe under 24/7 sanitisation. There are inherent problems associated with the tested hypochlorite sanitizer as this once sprayed over the infected places do not have a lasting effect. Furthermore, each repeat in such purging requires pre-evacuation of the affected building. In addition, frequent use of hypochlorite may have other ramifications causing chlorine related respiratory problems. Further, hypochlorite destroys plant habitation and transforms certain organic molecules as a carcinogen. ${ }^{3,4}$ To avoid such deleterious effects the alternate sanitizer, hydrogen peroxide, may be used as a safer disinfectant. The only problem it faces for its mass scale use as on dilution with water, it decomposes fast into oxygen and water due to the presence of catalytic amount (ppm level) of common transition metal ions in water. ${ }^{5,6}$ To overcome these adversaries, a sustained hydrogen peroxide generator would be helpful. A nano catalytic system is thus visualized to perform this task which is cheap to synthesize and is non-toxic to fauna and flora including humans. ${ }^{7-13} \mathrm{We}$ report herein the use of such water-soluble nitrogendoped (originated from grass chlorophyll) carbon nano onion (CNO) from a cheap source like grass by 
carbonizing it and by selective oxidation ${ }^{8,14}$ to get this in the average size around $100 \mathrm{~nm}$.

\section{Experimental}

\subsection{Synthesis}

The synthesis of such spontaneous nitrogen-doped CNO was made by following our established method using wood wool to synthesise CNO. ${ }^{8}$ The starting material is only dried green grass instead of wood wool which contains nitrogen in the chlorophyll ring and so it is imbibed as hetero atom in the carbon frame as found by XPS study. The detailed microscopic and spectroscopic characterization has been presented in Figure 1. We have already demonstrated that such nano carbons are non-toxic in the study of the entire life cycle of Drosophila melanogaster, E. coli and also in plant systems. ${ }^{7-14}$ Interestingly, while our work was in progress a separate publication to achieve nano carbon sphere indirectly via the formation of carbon nanotube from grass appeared in the literature. ${ }^{15}$

\subsection{HA assay}

A study on the infectivity and HA assay on WSN virus (H1N1) with this CNO has been carried out.
Lyophilized CNO was dissolved in PBS-pH 8 to create its concentration of $1 \mathrm{mg} / \mathrm{mL}$. WSN influenza virus was diluted to $1 \mathrm{HAU}$ ( $\left.\sim 10^{\wedge} 5 \mathrm{PFU}\right) .50 \mu \mathrm{L}$ of virus mixed with $50 \mu \mathrm{L}$ of $\mathrm{CNO}$ (final $\mathrm{CNO}$ concentration was $1 \mathrm{mg} / \mathrm{mL}$ ) and incubated at $37^{\circ} \mathrm{C}$ for $0 \mathrm{~min}$, $10 \mathrm{~min}, 30 \mathrm{~min}, 60 \mathrm{~min}, 90 \mathrm{~min}$ time. After the incubation time, a confluent monolayer of MDCK cells, which was seeded in 96 well plate the day before, was washed with PBS to remove the media and $40 \mu \mathrm{L}$ of the virus and $\mathrm{CNO}$ ( $\sim 0.4 \mathrm{HA}$ units) mix was added to the respective well and incubated with the cells for $60 \mathrm{~min}$. In this case, the time at which the virus was incubated with $\mathrm{CNO}$ has increased by 60 $\mathrm{min}$, for example, the virus incubated with $\mathrm{CNO}$ for 0 time has been incubated for $60 \mathrm{~min}$ extra, and so on for the other samples. After $60 \mathrm{~min}$ incubation with the cells, the inoculum was removed and the cells were washed again with PBS to remove any trace of CNO and unbound virus present, the DMEM media was added to cells and incubated for $72 \mathrm{~h}$ at $37{ }^{\circ} \mathrm{C}$. For the HA assay, after $72 \mathrm{~h}, 50 \mu \mathrm{L}$ of the cell supernatant for each time point was mixed with $50 \mu \mathrm{L}$ of Guinea pig RBC's in 96 well plate V bottom shape and incubated for $45 \mathrm{~min}$. The standard dilution strategy of the added reagents in different rows was made. However, the main issue here is to find out the inactivation of the virus in the presence of CNO. The virus was observed as inactivated by the $\mathrm{CNO}$, as the RBC's were settled
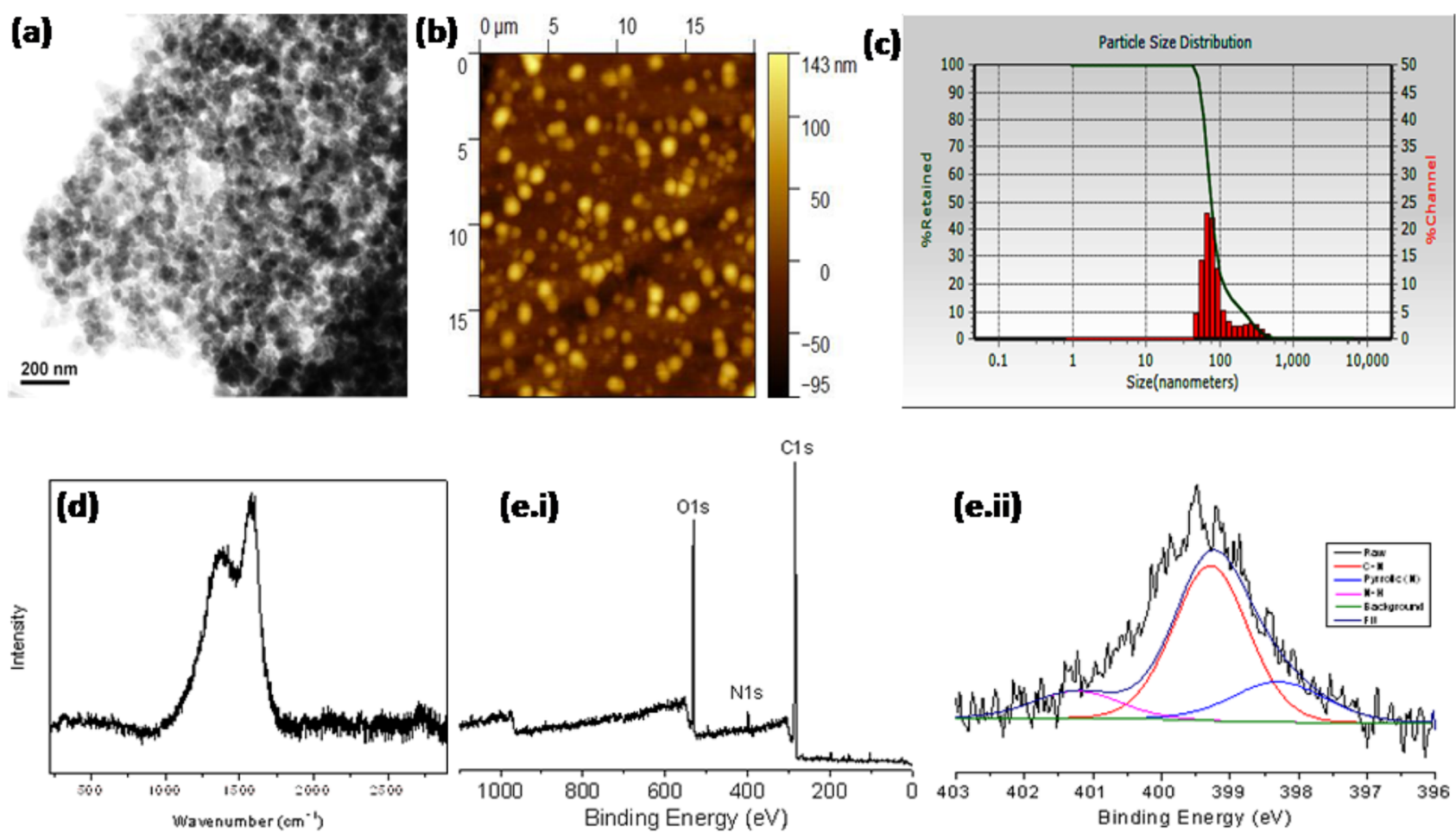

Figure 1. Characterization of CNO: (a) TEM, (b) AFM, (c) DLS, (d) RAMAN, (e,i) XPS, (e,ii) nitrogen, from chlorophyll of the grass $(\mathrm{N}: 3 \%$, rest is $\mathrm{C}: 75 \%, \mathrm{O}: 22 \%)$. For equipments details, see ref. $8,12,14$ 
down in the bottom of the well and formed a dot as shown in Figure 2.

\section{Results and Discussion}

The effectiveness to destroy RNA virus by CNO is related to auto generation of hydrogen peroxide. $\mathrm{CNO}$ utilises the basic molecules available in the environment like aerial oxygen, relative humidity and visible light which would be a win-win situation for everyone. Such peroxide generation is not dependent on external energy and could be applied by spraying its aqueous solution in remote places like ducts of the air conditioners, walls indoors and outdoors of any building and public transport carriers. Interestingly, under DLS study the hydrodynamic size range of this CNO became larger (from the size distribution as measured from TEM in the range 20 to $100 \mathrm{~nm}$ ) with optimum size distribution from $70 \mathrm{~nm}$ to $200 \mathrm{~nm}$ extending in low percentage particle size distribution to the higher range (Figure 1). With a high degree of surface charge (Zeta potential, $\sim-70 \mathrm{mV}$ ), the hydrodynamic size range cover the reported size of SARS-CoV-2. This will readily allow macromolecular collisions between $\mathrm{CNO}$ and H1N1 virus or SARS-CoV-2 involving electrostatic and hydrogen-bonding interactions.

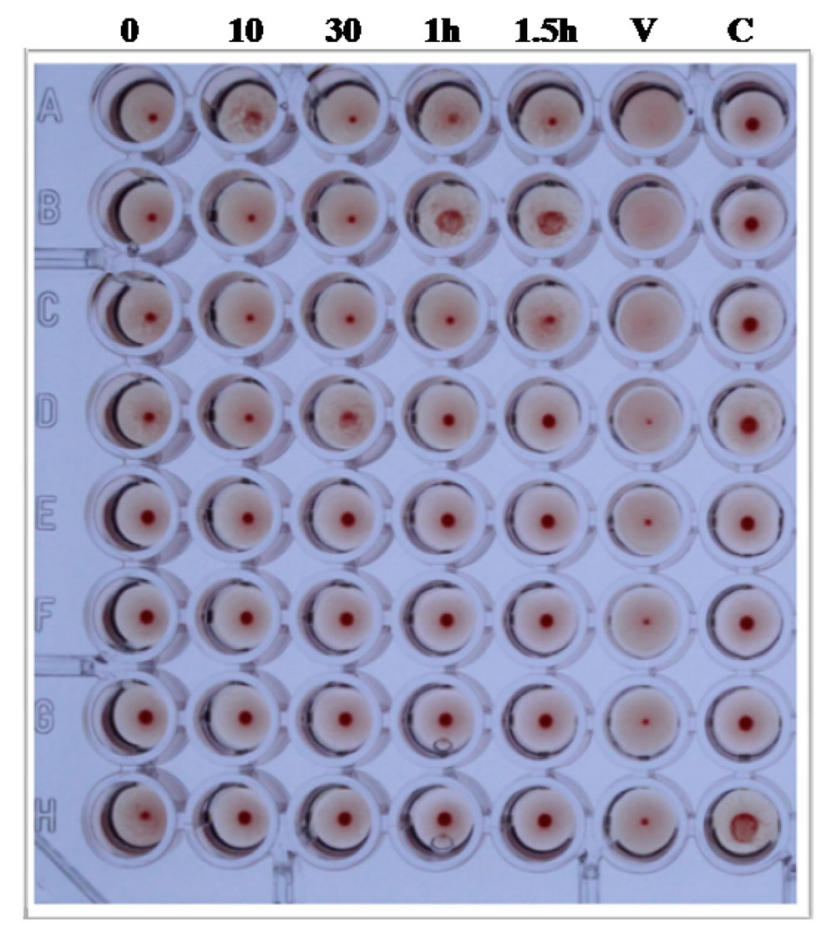

Figure 2. WSN virus (H1N1) incubated with $\mathrm{CNO}$ under different time exposure labeled channels (top) as $0,10,30$ $\min$ and $1,1.5 \mathrm{~h}, \mathrm{~V}$ : untreated virus control. The first three wells in the column without $\mathrm{CNO}$ show that the infection has occurred. C: Cell control.
Before invoking any such collision it may be visualized that $\mathrm{CNO}$ initially form an adduct with aerial oxygen: $\left\{\mathrm{CNO}+{ }^{3} \mathrm{O}_{2}=\mathrm{CNO} \|{ }^{3} \mathrm{O}_{2}\right\}$, which under visible light excitation activate the $\mathrm{CNO}$ to generate singlet oxygen followed by electron transfer: $\left\{\mathrm{CNO}^{+} \|{ }^{1} \mathrm{O}_{2}^{-}\right\}$, producing superoxide radicals. The superoxide radical anion disproportionates to peroxide or hydroperoxide ion and oxygen and finally to hydroxyl radical leading to the generation of all reactive oxygen species (ROS). The cascading generation of singlet oxygen, superoxide radical to peroxide has been tested by using classical inhibitors like azide, DMSO to establish the sequence of such reactions. ${ }^{16-18}$ The behaviour of present CNO is similar to reduced graphene oxide that shows ROS generation in combating hospital pathogen involving reduced graphene oxide. ${ }^{18-20}$ There is also a report that highly oxidized hydrophilic nanocarbon systems display a high affinity for electrons. Such nano carbons possess $\mathrm{O}_{2}$ reduction reaction capabilities to superoxide finally with the formation of $\mathrm{H}_{2} \mathrm{O}_{2}{ }^{21}$ A starch-iodide filter paper sprayed with $1 \%$ aqueous CNO under present study showed the development of blue colour within an hour indoor. We have checked this reaction using classical inhibitors like azide, DMSO to establish the sequence in the formation of superoxide to peroxide to hydroxyl radical involving the present CNO. This hydrogen peroxide generation has also been visualized in the development of blue coloration of the starch-iodide solution under exposure from $60 \mathrm{~W}$ tungsten bulb's light, as shown in Figure 3(a). The settled down precipitate obtained in the $\mathrm{HA}$ assay is comprised of RBC aggregate and the debris from the virus (mostly nucleic acid fractions, sugars and phosphates) along with some PBS buffer salts. In this mixture, the identification to understand the fate of the trace (catalytic amount) of CNO would be problematic. The best analytical tool of proving the morphology of $\mathrm{CNO}$ is either by SEM or AFM microscopy. However, the present insoluble mixture is heavily contaminated covering the trace amount of CNO and so the SEM (or AFM) will not image uniquely any signature of the used $\mathrm{CNO}$ rather its image will be smeared up by the dominant RBC debris and buffer salt used. Therefore, we used the iteration of CNO in the process of its sustained generation of hydrogen peroxide. The used $\mathrm{CNO}$ has been reused several times retaining its catalytic activity by refreshing the starch iodide solution. Thus, one may envisage that the ROS generating $\mathrm{CNO}$ with its peripheral hydroxyl and carboxylic acid groups may interact with the RNA virus. Normally H1N1 virus is shown to interact with drugs or other material dominantly by hydrogen bonds ${ }^{22}$ so in the present case the 


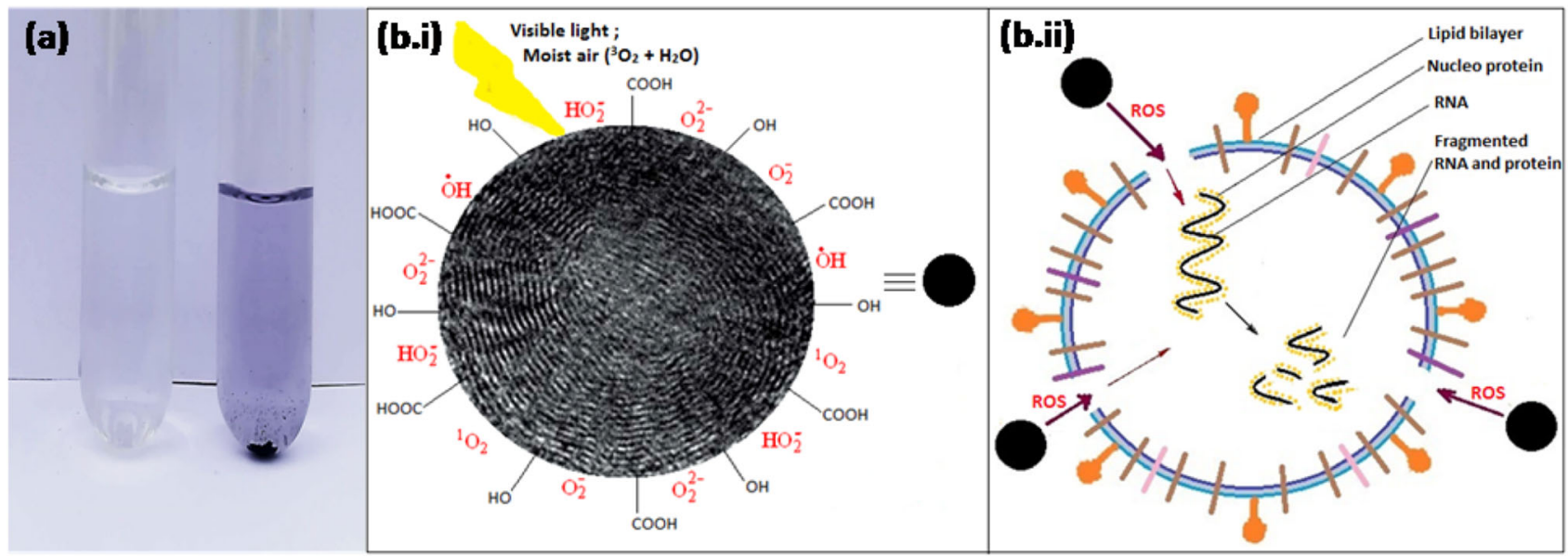

Figure 3. (a) left: starch-iodide solution as control; right: starch-iodide solution with CNO. Both are under 60 Watt tungsten lamp exposures at a distance of one meter. The blue color developed with such exposure within $2 \mathrm{~h}$ indicates the generation of hydrogen peroxide. (b.i) exposure of light on CNO in air generate ROS (b.ii) CNO with ROS collide with SARS-CoV-2 to rupture lipid layer and disintegrate virus RNA.

CNO with its peripheral hydrophilic functional groups may be ideal to interact with HINI virus forming adducts. Such an adduct is capable to generate hydrogen peroxide from the CNO part induced by light in air to destroy the attached HINI virus. This explains our result from the HA assay.

$\mathrm{H}_{2} \mathrm{O}_{2}$ is known as the most natural and safe chemical to eradicating COVID-19. ${ }^{23}$ Such an eradication process may involve first the rupture of the lipid layer of SARS-CoV-2. CNO generated hydrogen peroxide is known to destroy lipids in pathogens. ${ }^{19,20}$ Also the denaturation and deactivation of ds-DNA under similar light-induced interaction with $\mathrm{CNO}$ were reported. $^{24}$ Therefore, the mode of action of hydrogen peroxide to destroy SARS-CoV-2 may be envisioned as follows. The lipid layer of SARS-CoV-2 has several pockets to invite hydrogen bond interactions with hydrophilic CNO leading to adduct formation. Under the influence of visible light and aerial oxygen, the spontaneous generation of hydrogen peroxide by $\mathrm{CNO}$ in the adduct may induce the rupture of the lipid layers followed by disintegrating the fragile virus RNA. This eradication process of the virus is pictorially shown in Figure 3(b).

\section{Conclusions}

In conclusion, we describe a hydrogen peroxide generating nanocatalyst, nitrogen-doped $\mathrm{CNO}$, which can be prepared from simple pyrolysis of dry grass followed by controlled oxidation of the charred mass. This being fairly water-soluble can be sprayed as hydrogen peroxide generating sanitizer avoiding the frequent use of hypochlorite solution which has an adverse effect on excess use. An interesting property of this $\mathrm{CNO}$ is its $\mathrm{pH}$-dependent solubility. Because of the presence of several electrophilic hydroxyl and carboxylic groups attached to its surface, it goes into solution in the $\mathrm{pH}$ range above 8 due to the deprotonation of several such groups. Below $\mathrm{pH} 7$ it becomes insoluble (without sonication) due to protonated form of these groups followed by condensation of some of the adjoining hydroxyl groups to epoxy form. This results in an overall change in the geometric shape of $\mathrm{CNO}$ which we have already addressed in the related system. ${ }^{25,26}$ Such behaviour may be exploited by spraying water-soluble CNO dissolved around $\mathrm{pH} \geqslant 8$. This when sprayed on the walls and other surfaces of concern will react with atmospheric carbon dioxide to lower the $\mathrm{pH}$ transforming this soluble form into insoluble deposition. This is important for its adherence on the surface of the hospital walls both indoor and outdoor and in the installed vents of the central air circulating system, be it a hospital, building or travel carriers. This will lead to its sustained catalytic action to release uninterrupted hydrogen peroxide. Such action is most desirable in the present COVID-19 pandemic scenario where frequent spraying hypochlorite disinfectant with human evacuation may be avoided. Its use indoors will create virusfree surroundings for the health personnel and patients or people inside any hospital or quarantine centres under auto sterilized aerosol environment for a long time. 


\section{Acknowledgements}

S.S. thanks Prof. R. Varadarajan and Dr. K. Kanjo of Molecular Biophysics Unit, Indian Institute of Science Bangalore 560012 confirming our proof of concept using the CNO in the infectivity and HA assay on WSN virus (H1N1) study, described herein. A. S. thanks the Department of Science and Technology, Government of India, New Delhi in receiving an INSPIRE Fellowship (IF170359).

Authors Contributions SS designed the experiments, analysed the data and wrote the final manuscript, AS performed the experiments, procured the data and helped to make the draft of the manuscript and SG performed experiments.

\section{Declarations}

Conflict of interest There are no conflicts to declare.

\section{References}

1. Coronavirus disease (COVID-19) advice for the public. https://www.who.int/emergencies/diseases/novel-coro navirus-2019/advice-for-public. Accessed 25 July 2021

2. Coronavirus disease (COVID-19) Pandemic. https:// www.who.int/emergencies/diseases/novel-coronavirus2019. Accessed 25 July 2021

3. Dunnick J K and Melnick R L 1993 Assessment of the carcinogenic potential of chlorinated water: experimental studies of chlorine, chloramine, and trihalomethanes J. Natl. Cancer Inst. 85817

4. Prasse C, Gunten U V and Sedlak D L 2020 Chlorination of Phenols Revisited: Unexpected Formation of $\alpha$, $\beta$-Unsaturated $\mathrm{C}_{4}$-Dicarbonyl Ring Cleavage Products Environ. Sci. Technol. 54826

5. Sigel H, Flierl C and Griesser R 1969 Metal ions and hydrogen peroxide. XX. On the kinetics and mechanism of the decomposition of hydrogen peroxide, catalyzed by the $\mathrm{Cu}^{2+-}$ 2,2'-bipyridyl complex J. Am. Chem. Soc. 911061

6. Salem I A, El-Maazawi M and Zaki A B 2000 Kinetics and mechanisms of decomposition reaction of hydrogen peroxide in presence of metal complexes Int. J. Chem. Kinet. 32643

7. Sonkar S K, Ghosh M, Roy M, Begum A and Sarkar S 2012 Carbon Nano-Onions as Nontoxic and HighFluorescence Bioimaging Agent in Food Chain-An In Vivo Study from Unicellular E. coli to Multicellular C. elegans Mater. Express 2105

8. Ghosh M, Sonkar S K, Saxena M and Sarkar S 2011 Carbon Nano-onions for Imaging the Life Cycle of Drosophila Melanogaster Small 73170

9. Saxena M and Sarkar S 2014 Involuntary graphene intake with food and medicine RSC Adv. 430162

10. Sonkar S K, Roy M, Babar D G and Sarkar S 2012 Water soluble carbon nano-onions from wood wool as growth promoters for gram plants Nanoscale 47670

11. Saxena M, Maity S and Sarkar S 2014 Carbon nanoparticles in 'biochar' boost wheat (Triticum aestivum) plant growth $R S C A d v .439948$
12. Bhati A, Gunture, Tripathi K M, Singh A, Sarkar S and Sonkar S K 2018 Exploration of nano carbons in relevance to plant systems New J. Chem. 4216411

13. Pakhira B, Ghosh M, Allam A and Sarkar S 2016 Carbon nano onions cross the blood brain barrier $R S C$ Adv. 629779

14. Tripathi K M, Bhati A, Singh A, Sonker A K, Sarkar S and Sonkar S K 2017 Sustainable Changes in the Contents of Metallic Micronutrients in First Generation Gram Seeds Imposed by Carbon Nano-onions: Life Cycle Seed to Seed Study ACS Sustain. Chem. Eng. 5 2906

15. Ma Y, Lu N, Lu Y, Guan J, Qu J, Liu H, et al. 2016 Comparative Study of Carbon Materials Synthesized "Greenly" for 2-CP Removal Sci. Rep. 629167

16. Franco R, Panayiotidis M I and Cidlowski J A 2007 Glutathione depletion is necessary for apoptosis in lymphoid cells independent of reactive oxygen species formation J. Biol. Chem. 28230452

17. Maher B A, Ahmed I A M, Karloukovski V, MacLaren D A, Foulds P G, Allsop D, et al. 2016 Magnetite pollution nanoparticles in the human brain Proc. Natl. Acad. Sci. U S A 11310797

18. Pakhira B, Kumbhakar I, Samanta A, Das G S and Sarkar S 2018 Indoor Floating Dust Contains Graphene Derivative to Generate Reactive Oxygen Species with Visible Light and Oxygen Mater. Today Proc. 5 10131

19. Dutta T, Sarkar R, Pakhira B, Ghosh S, Sarkar R, Barui A and Sarkar S 2015 ROS generation by reduced graphene oxide (rGO) induced by visible light showing antibacterial activity: comparison with graphene oxide (GO) RSC Adv. 580192

20. Maity S, Pakhira B, Ghosh S, Saha R, Sarkar R, Barui A and Sarkar S 2017 Microcarbon-based facial creams activate aerial oxygen under light to reactive oxygen species damaging cell Appl. Nano Sci. 7607

21. Jalilov A S, Zhang C, Samuel E L G, Sikkema W K A, Wu G, Berka V, et al. 2016 Mechanistic Study of the Conversion of Superoxide to Oxygen and Hydrogen Peroxide in Carbon Nanoparticles ACS Appl. Mater. Interfaces $\mathbf{8} 15086$

22. Le L, Lee E, Schulten K and Truong T N 2009 Molecular modeling of swine influenza A/H1N1, Spanish H1N1, and avian H5N1 flu N1 neuraminidases bound to Tamiflu and Relenza PLoS Curr. 4

23. Kampf G, Todt D, Pfaender S and Steinmann E 2020 Persistence of coronaviruses on inanimate surfaces and their inactivation with biocidal agents J. Hosp. Infect. 104246

24. Babar D G, Pakhira B and Sarkar S 2017 DNAcarbon nano onion aggregate: triangle, hexagon, sixpetal flower to dead-end network Appl. Nano Sci. 7 291

25. Pakhira B, Ghosh S, Maity S, Sangeetha D N, Laha A, Allam A and Sarkar S 2015 Extraction of preformed graphene oxide from coal: its clenched fist form entrapping large molecules RSC Adv. 589076

26. Pakhira B, Samanta A, Das G S and Sarkar S 2017 Graphene oxide: A No-Acid Low-Temperature Synthesis from Graphite ChemistrySelect 25564 